\title{
Let's get personal: A call for personalised pedagogy
}

\section{Diana Bath}

\author{
University of Greenwich, School of Education
}

\section{Abstract}

This paper seeks to open a dialogue around the process of inspiring life-wide learning. It aims to share a dialogue that began within one of the Inspiring Learners conference workshops, so as to generate discussion between colleagues in the fi eld of education. It argues that the process of becoming inspired is essentially an affective or emotional engagement that happens within the learner's embodied experience. It explains why the impact of such learning may be life-wide. Paradoxically, this paper also suggests that our life-wide experiences may act as a barrier to our learning process.

\section{Introduction}

The focus of this discussion falls around what educators need to understand about the learning process. The notion of inspired learning is framed around an affective engagement in a personal learning process. It suggests that cognitive development should not be considered in isolation from emotional, physical and social aspects of the learning process.

The discussion centres around embodied-learning encounters, drawing on experiential learning and transformational learning theories (Mezirow, 2009). My motivation to do so is to develop a more personalised teaching pedagogy that moves beyond notions of knowledge transfer to incorporate personal transformations. The purpose of this paper is to serve as an extended 'thought piece'. It highlights the need for further investigation into the learner's experience to form qualitative research narratives in support of improved practice.

\section{Personal context}

This piece reflects aspects of my current thinking based upon my own life-wide learning. The paper draws on my Master's degree research surrounding dance movement psychotherapy (DMP) and its application 
within educational settings. As a newly qualified dance movement psychotherapist, I would describe my approach as one which incorporates a mindfulness of the body in what it senses and communicates nonverbally. In a therapeutic context this allows people to explore and understand the experiences that make them who they are. In many ways this is reminiscent of a self-learning process leading to increased personal and social awareness. It creates opportunity for increased personal integration and individuation.

The following discussion uses the concept of 'embodiment' as borrowed from educational and dance movement psychotherapy discourse to draw attention to the felt and lived experience of the learner.

This paper will not be discussing DMP but will draw on reading that has influenced me over the course of my studies. Having integrated my learning as a trainee dance movement psychotherapist into my personal development, I fi nd that the way I think about teaching and learning has been affected by my experiences. I am immediately struck by the parallels that exist between my learning and professional development and that of my students. I have become aware of my own creative process as I personalise my teaching pedagogy. Whilst I maintain the view that therapy and education are distinct disciplines that should not be confused, I continually ask myself how I can apply notions of personal development in therapeutic contexts to transformational learning in educational contexts.

\section{Starting with the conference}

As the workshop began, participants arrived to the sound of music playing. When asked what effect the music had as they entered, some spoke about having formed expectations about myself and my session. One group member said she interpreted the music as a sign that I was well prepared and that I was someone who tried to make learning fun. There was a clear correlation drawn between having fun and learning. However, our later discussions challenged this view. When asked to recall a key learning experience, it soon came to light that the lived experience of learning included the whole range of affects and emotions, many of which were far from fun and sometimes overwhelming. We started to see that in many of our life stories our expectations of how learning ought to be led to disappointments in reality. Often success required overcoming fears and failings.

My conviction is that the emotional aspect of learning is often disregarded and yet it may be the most common barrier that learners face. It is necessary to explore the physiological basis of the emotions in order to understand that they provide useful sources of information and are the key to our embodied learning transformations. If emotional responses to learning are not integrated then the learning process may not be complete. The learner may fi nd their learning unsustainable and may look for ways to leave or disengage. 


\section{Affective learning}

Educational discourse tends to marginalise the emotions to discussions around emotional and behavioural disorders and emotional literacy. This raises a number of concerns. Firstly, that the emotions are relegated to those who have/work with special education needs. Secondly, there is a tacit suggestion that everyone should learn to be happy and that diffi cult emotions are unwelcome. This leads to a more worrying assumption that by teaching emotional literacy, a child may learn to disassociate from their true feelings in order to conform to a prescribed emotional 'grammar'. Whilst these discourses provide a valuable understanding for specifi c learning contexts, there is a danger that the emotions might also be reduced to the ingredients of a positive or negative classroom climate. Teachers may be forgiven for trying to eliminate negative emotions from the classroom whilst focussing on creating feelings of motivation and excitement. Certainly a happy or excited group of learners presents a positive impression to teachers and inspectors, but does this allow for learning to be fully internalised so that learning may be life-wide?

The dominant discourse in education frames learning as something that is largely disembodied from physical experience. If this were not the case then our learning spaces might look and function differently. There could be more attention drawn to the relationship between physical activity and mental activity and there could be a greater capacity for integrating the two. This paper suggests a focus of this nature might support a more permanent development in a person's abilities. This model therefore challenges the notion that learners are taught and replaces it with a more complex learning relationship. In this case notions of embodied learning contribute to a more affective learning process.

\section{Embodied experience as the foundation of learning}

To be embodied one needs to have an awareness of being in the body. An embodied learning experience might be seen as an experience that goes beyond the use of a kinaesthetic learning activity. Instead, the learner may use their 'felt sensations' to bring awareness to their body, mind and emotional states as they become engaged and transformed by learning. In recognising that experience comprises a complex web of these three physiological, mental and affective states, which are of course variable over time, a question arises as to how these three levels of experience become integrated? How does the learner make sense of their cognitive development in the presence of their felt-sensations and perceptions? How is learning made to be transformational on a personal and therefore life-wide level?

Key concepts within this view are embodied or somatic knowledge, and the experiential nature of learning. These may be related to developmental models of learning. Learning is largely perceived as an intellectual activity located in specifi $c$ and localised areas in the brain. Neuroscience now offers a more complex 
picture of how the mind and the systems within the body interact. Embodied or 'somatic' learning is a process that uses the senses and perception in mind/body action and exists within an existential whole; integrating current learning with the learner's experiential life history. Embodied learning stands on the shoulders of Merleau-Ponty's (1962) phenomenological philosophy which sees the learner as being situated within both external and internal lived (singular and collective) experience, which through the body's mediation, shapes behaviours and ways of relating with others, artefacts and organisations (Kupers 2008).

It would seem an obvious observation to make that the human way of experiencing the world is fundamentally dependent on the unique sensory perceptions of the human body and the brain. It would make no sense then to imagine that learning is in any way disembodied, and yet educated society seems to behave as if it were. Bodily action is often seen by educators as a distraction from dispassionate logical thought. Prevailing philosophies that honour the 'mind' over the 'fl esh' and the 'intellect' over 'subjective feelings and emotion', echo aspects of 17 th century Cartesian philosophy.

Western culture is perhaps dominated by a perceived split between cognitive knowledge and embodied knowledge which can often be denigrated as something that needs to be tamed or controlled. However, through developments in mind/body research and advances in postmodern feminist discourse, the concept of embodied learning has surfaced in the fi eld of adult education, highlighting some critical issues. Firstly, the recognition of the body as a source of knowledge enables the use of increased bodily awareness to challenge dominant discourse. Also, the use of embodiment may be used to develop empathy and respect diversity which promotes new and more complex knowledge and understanding.

Whilst bodily knowing is only one of the many dimensions of human knowing, which also includes dimensions such as cultural, psychological, and linguistic dimensions, it incorporates and extends beyond that of kinaesthetic intelligence. It also goes beyond what has become known as the 'tactile' or kinaesthetic learning style.

It is also interesting to note that in trying to make sense of our experience we refer to metaphors, based in our familiar embodied experience. For example, we might feel like we are the 'slow coach' or the 'rising star' as we grapple with our learning objective. It would seem relevant to comment on the variety of ways we perceive ourselves, and our relationships with others, within the context of a 'system' of learning. The implication is that if personal relationships, such as the teacher/learner dyad, or relationship with self, provide the critical structures in forming a learning experience, then one must look at how we come to know if our relationships are working for us or against us. This is where refl ection on the role of the emotions may become a useful indicator. 


\section{Experiential learning as part of a life-wide process}

Kolb roots his experiential learning theory in John Dewey's philosophy of education. However, Elkajaer (2009) points out that Kolb's use of the term experience strays some distance from Dewey's use of the term. For example, Kolb and his followers perceive experience as knowledge and as isolated events oriented in the past. Traditional concepts of experience thus follow Kolb's notions of experience as beingactive and subjective (Elkjaer, 2009).

Dewey, on the other hand, saw knowledge as just one subset of experience which he thought of in terms of the potential for future experiences. He also recognised that experience, like knowledge, can be both subjective and objective. Rather than seeing experience as a series of isolated experiences, Dewey focused on united experiences that went beyond actions to encompass concepts as a foundation for knowledge (Elkajaer, 2009). The latter view of experience lends itself to a fresh look at learning experience within the context of lifelong learning.

Jarvis (2009) agrees that 'learning is both existential and experiential.' Jarvis describes a recent shift in his thinking to accommodate a philosophical belief that whilst a learner is learning new knowledge and skills they are also learning to be and learning to become their full self. Whilst the notion of becoming is not new to lifelong learning, this shift is eloquently explained in the elaboration of learning as "the transformation of experience into knowledge, skills and attitudes" into "Human learning is the combination of processes throughout a lifetime whereby the whole person - body (genetic, physical and biological) and mind (knowledge, skills, attitudes, values, emotions, beliefs and senses) - experiences social situations, the perceived content of which is then transformed cognitively, emotively or practically (or through any combination) and integrated into the individual person's biography resulting in a continually changing (or more experienced) person" (Jarvis 2009).

It is seen that the impact of learning on a person's biographical story is significant. At the same time the person's biographical experience and past learning impacts on the current learning experience.

\section{Personal process and paradox}

The term 'learning process,' is used both as verb and noun. This suggests that it is conceptually variable. We are simultaneously the agents and recipients of our learning experience. There is a similar dichotomy in the way we experience ourselves within the learning process. Do we view ourselves as a work in progress or do we measure ourselves by our perceived performance? Is it possible to think of ourselves in both ways at the same time? In Jungian psychology there is an opportunity to expose these kinds of issues as "conglomerates of contradictory elements" (Singer Harris, 1996). Jung suggested that life is full of paradox; 
that every individual is conflicted by contradictory experiences such as conscious thoughts versus unconscious attitudes. As a teacher I ask myself how the unconscious aspects of my own attitudes and projections contribute to the learning situation. I use my 'felt sense' to consciously interpret the non-verbal communications of my students; to attune to their affective state so that I may provide a more containing environment for them to take the risk of failure as they embark on their learning.

For many of us the Jungian 'shadow' may have already broken through into our consciousness. We know about our ambivalence; the fact that we want to learn but we do not want to learn. In such instances Illeris (2009) suggests that a transformative learning experience may be just what is needed. However, he warns that in most cases transformation only comes when a person reaches a personal crisis point.

\section{Ambivalence and resistance as barriers}

It is useful to remember that in all cases of learning a person's lived experience may collude with situational learning barriers resulting in unhappy learners who are difficult to retain. Illeris (2009) suggests that in some cases of extreme resistance to learning one cause may be an identity defence. This happens when a learner faces a dramatic and unwelcome shift in his or her circumstances. Another form of defence is ambivalence, where one is both wanting and not wanting to learn. In addition, there is a kind of mental resistance that does not happily accept the 'right' answers being given. Illeris explains that in order to prevent information overload people create a semi-automatic sorting system that involves measuring new information to pre-conceived understanding. Often where there is no comfortable fit information is either distorted or rejected. Through this means learners decide what learning is relevant to them and what is within their reach (Illeris 2009).

In this instance one may refer to Mezirow's notion transformational learning which involves a change in one's meaning perspectives or habits of mind. Such an internal frame of reference may include a predisposition to categorise people, events beliefs and experiences in a certain way (Mezirow 2009). It may be plausible to suggest that in some cases, a person's frame of reference may itself become a barrier to learning, if the nature of that learning is so different to the past. To overcome this predisposition Illeris suggests that the learner needs to engage in some critical self-reflection and corresponding action. "Our experiences of persons, things and events become realities as we typify them. This process has much to do with how we come to associate them with our personal need for justification, validity and a convincing, real sense of self" (Mezirow, 2009). It may be concluded that a learner's expectations and meaning perspectives can powerfully influence the way they construe experience, despite the fact that this mostly happens outside of their conscious awareness. This is also true of learning experience. 


\section{A call for personalisation}

Across the education system in the UK we have seen persistent drives to promote individualised learning. From the Early Years Foundation Stage (DCSF, 2008) based on the principle of a unique learner, to the previous government's 2020 Vision Report of the Teaching and Learning Review Group (DFES, 2006) it has been widely accepted that standardisation of teaching does not result in equity for learners. However, it might be considered that individualised learning is rather a policy-driven, institutionalised concept and may not go far enough. Although the terms individualised and personalised learning are used interchangeably, my point is that the focus is almost exclusively on the learner's learning outcomes. The way the learner is viewed is therefore shaped by a curricular or programme design. This idea may be somewhat reductive and rather imposed upon them. There is limited recognition of a teacher's right to personalisation, and the joys and challenges of being together in a learning process. For me the notion of personalised pedagogy goes further in recognising both the learning partnership and the whole person; not reducing the learning context to a set of learning needs and strategies. Personalised learning calls for personalised pedagogies. This challenges the traditional power dynamic of the teacher-learner relationship by reframing them as partners in their learning narratives.

A redistribution of power in the teacher and learner relationship may however pose some challenges. Whilst many educators are willing to support learners in making decisions about what style and scope of learning may be relevant to them, for some educators there may be a diminished sense of professional judgement and status. Indeed, revisions to what is deemed valuable learning experience may not be easily reconciled with current models of quality assurance. Personalised pedagogy does not sit comfortably with a 'one size fi ts all' approach to inspection, as has been endorsed in some ways by successive governments.

\section{Conclusion}

This paper presents an embodied approach to teaching and learning. Embodiment is presented as a means to judge and understand a learner's affective engagement within their personal learning journey. The discussion suggests that educators may benefi t from an increased awareness of the emotional aspects to learning, in particular transformative learning. This may empower teachers and learners in their parallel processes of building new understandings of how they can improve. This is important if educators are to inspire their learners and unlock their life-wide potential. A failure to do so may have an impact on learner engagement, achievement and overall student satisfaction. In post-compulsory settings, increased awareness may also strengthen recruitment and retention. Perhaps a more personal touch is the way forward. 
Compass: The Journal of Learning and Teaching at the University of Greenwich, Issue 3, 2011

\section{References}

Elkjaer, B. (2009) 'Pragmatism: a learning theory for the future.' In: Illeris, K. (ed) Contemporary Theories of Learning. Oxford: Routledge.

Illeris, K. (2009) 'A Comprehensive Understanding of Human Learning'. In: Illeris, K. (ed) Contemporary Theories of Learning. Oxford: Routledge.

Jarvis, P. (2009) 'Learning to be a Person in Society.' In: Illeris, K. (ed) Contemporary Theories of Learning. Oxford: Routledge.

Kupers, W. (2008) 'Embodied "inter-learning”- an integral phenomenology of learning in and by organisations.' The Learning Organisation. 15 (5), 388-408.

Merleau-Ponty, M. (1962) Phenomenology of Perception, trans. Smith, Colin. London: Routledge and Kegan Paul.

Mezirow, J. (2009) 'An overview of transformative learning' In: Illeris, K. (ed) Contemporary Theories of Learning. New York \& Abingdon: Routledge.

Singer Harris, A. (1996) Living in Paradox. An Introduction to Jungian Psychology. London: Int. Thomson. 